SAND80-8201

Unlimited Release

\title{
DIFFUSE: A Code to Calculate One-Dimensional Diffusion and Trapping
}

\section{MASTER}

M. I. Baskes

Sandia Laboratories

Sf $2900 \mathrm{Q}(7.73)$ 
Issued by Sandis Laboratories, operated for the United States Department of Energy by Sandia Corporation.

\section{NOTICE}

This report was prepared as an account of work sponsored by the United States Government. Neither the United States nor the United States Department of Energy, nor any of their employees, nor any of their contractors, subcontractors, or their employees, makes any warranty, express or implied, or assumes any legal liability or responsibility for the accuracy, completeness or usefulness of any information, apparatus, product or process disclosed, or represents that its use would not infringe privately owned rights. 


\section{DISCLAIMER}

This report was prepared as an account of work sponsored by an agency of the United States Government. Neither the United States Government nor any agency Thereof, nor any of their employees, makes any warranty, express or implied, or assumes any legal liability or responsibility for the accuracy, completeness, or usefulness of any information, apparatus, product, or process disclosed, or represents that its use would not infringe privately owned rights. Reference herein to any specific commercial product, process, or service by trade name, trademark, manufacturer, or otherwise does not necessarily constitute or imply its endorsement, recommendation, or favoring by the United States Government or any agency thereof. The views and opinions of authors expressed herein do not necessarily state or reflect those of the United States Government or any agency thereof. 


\section{DISCLAIMER}

Portions of this document may be illegible in electronic image products. Images are produced from the best available original document. 
SAND 80-8201

UNLIMITED RELEASE

PRINTED JANUARY 1980

\title{
DIFFUSE: A CODE TO CALCULATE ONE-DIMENSIONAL \\ DIFFUSION AND TRAPPING
}

\author{
M. I. Baskes \\ Sandia Laboratories \\ Livermore, Cal ifornia 94550
}

\begin{abstract}
This document is intended to briefly acquaint the reader with the computer code DIFFUSE. DIFFUSE may be used to calculate the one dimensional diffusion, and trapping of atoms in a material under general initial, source, and boundary conditions. The document includes a description of the physical model, code input and output format, three typical sample problems and their output, a listing of the code, and the control cards needed to use DIFFUSE at Sandia Laboratories Livermore.
\end{abstract}

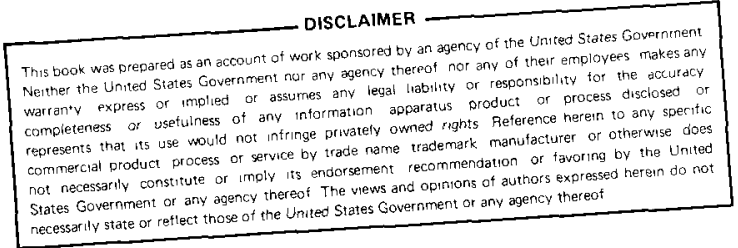

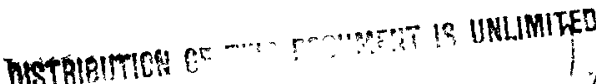




$$
\because
$$

,

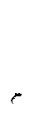

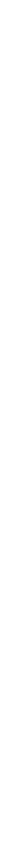

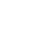




\section{Introduction}

This document is intended to briefly acquaint the reader with the computer code DIFFUSE. DIFFUSE may be used to calculate the one dimensional diffusion, and trapping of atoms in a material under general initial, source, and boundary conditions. A basic familiarity with the physics of diffusion, trapping, and implantation, and the numerical solution techniques of partial differential equations is assumed. This code is available for distribution from the author. Section II presents the assumed physical model while Section III presents the code input and output format. Section IV contains three typical sample problems; an implantation and desorption; a high temperature charge and cool down; and an example of cycled implantation. Appendix A contains a list of the control cards needed to use DIFFUSE at SLL. A listing of the program plus the output created by the sample problems may be found on the microfiche included with this document. Appendix B contains an index of the program.

\section{Physical Model}

The physical model presented here is intended to be a one dimensional simulation of any combination of the following processes:

1) bulk diffusion,

2) bulk trapping and detrapping,

3) tritium decay resulting in trapped helium at birth.

The source of the diffusing species may be from any combination of:

1) implantation

2) diatomic gas phase entry at surfaces

3) initial concentration

Sample geometry may be:

1) a semi-infinite slab 
2) a solid or hollow cylinder

3) a solid or hollow sphere

The definitions of the symbols used below are given in Table I. The basic equations to be solved are given by:

$$
\begin{aligned}
\frac{\partial c(x, t)}{\partial t}=\nabla & \cdot[D(T(t)) \nabla c(x, t)]+G(x) \\
& -\Sigma_{\mathbf{i}} \frac{\partial c_{T}^{i}(x, t)}{\partial t}
\end{aligned}
$$

Which is Fick's Law with source and trapping terms, where, for the $i$ th type of trap,

$$
\begin{aligned}
\frac{\partial c_{T}^{j}(x, t)}{\partial t}= & D(T(t)) c(x, t) C_{T_{e}}^{i}(x, t) / \lambda^{2} \\
& -c_{T}^{i}(x, t) \nu_{0} \exp \left[-\left(E_{T}^{i}+Q_{D}\right) / k T(t)\right]
\end{aligned}
$$

$$
C_{T_{e}}^{i}(x, t)=C_{T_{0}}^{i}(x)-f^{i} C_{T}^{i}(x, t)
$$


When tritium decay is included:

$$
\frac{\partial c_{T}^{i}(x, t)}{\partial t}=\gamma c(x, t)
$$

where helium is considered as a "trapped" tritium.

The material is assumed to obey a classical Arrhenius behavior for the diffusivity and solubility, i.e.:

$$
\begin{aligned}
& D(T)=D_{0} M^{-\frac{1}{2}} \exp \left(-Q_{D} / k T\right) \\
& S(T, P)=S_{0} P^{\frac{1}{2}} \exp \left(-Q_{S} / k T\right)
\end{aligned}
$$

The initial conditions are specified as:

$$
\begin{aligned}
& c(x, 0)=c_{0}(x) \\
& c_{T}^{i}(x, 0)=c_{T_{0}}^{i}(x)
\end{aligned}
$$

The boundary conditions may be any of the following:

$$
c\left(x_{s}, t\right)=0
$$

zero surface concentration,

$$
c\left(x_{S}, t\right)=S(T(t), P(t))
$$

Sievert's Law, 


$$
\left.\nabla c(x, t)\right|_{x_{s}}=0
$$

zero surface flux (reflecting barrier),

$$
\left.\nabla c(x, t)\right|_{x_{S}}=B(T(t))\left[\left(\frac{c\left(x_{s}, t\right)}{S(T, 1)}\right)^{2}-P(t)\right]
$$

surface recombination of a diatomic molecule, where

$$
B(T)=\frac{2 \alpha c_{1} \exp \left(-E_{x} / k T\right)}{\rho \sqrt{2 M T} D(T)}
$$

and the surface barrier $E_{x}$ is given by:

$$
E_{X}=\operatorname{MAX}\left(Q_{S}+Q_{D}, 0\right)
$$




\section{Code Utilization}

\section{A. Code Input}

The implant source $G(x)$ and trap $C_{T}^{j}(x)$ distributions are read from input as follows:

1) Identifier beginning in column 1 of "IMPLANT" for $G(x)$ or "TRAP" for $C_{T}^{i}(x)$

2) Depth (in $\AA$ ) and value of $G(x)$ or $C_{T}^{i}(x)$ (arb units) in (2F10.0) format. A maximum of 100 depth cards for each identifier allowed. The total number of implanted atoms $/ \mathrm{cm}^{2}$ and traps $/ \mathrm{cm}^{3}$ will be read in below.

3) Each data set ends with a negative depth.

4) "END" in column 1 to specify end of distributions. Note: These distributions may appear in any order (trap 1 becomes the first trap distribution read, etc.) and need not be present at all. The "END" identifier must appear however. A maximum of two trap distributions and one implant distribution is allowed.

Next information defining the sample and diffusing species is read from input in name list format:

\$SAMPLE

$$
\begin{aligned}
& E D=Q_{D}(0.5 \mathrm{eV}) \\
& D O=D_{0}\left(2.4 \times 10^{-3} \mathrm{~cm}^{2} \mathrm{AMU}^{\frac{3}{2}} / \mathrm{sec}\right) \\
& \text { ETRAP }=E_{T}^{i}+Q_{D}(0.85,0.85 \mathrm{eV}) \\
& \text { CTRAP }=\text { average trap concentration }(0.0,0.0 \text { atomic fract. })
\end{aligned}
$$




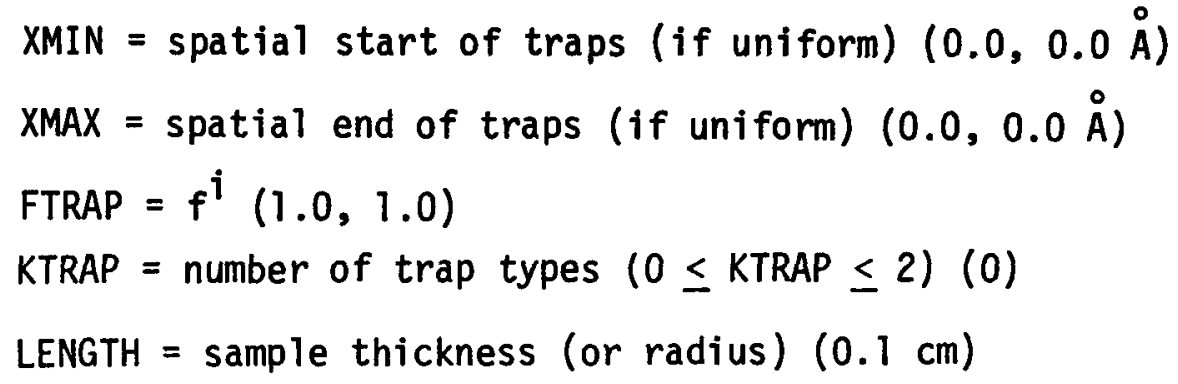

FRONT, BACK = boundary conditions to be used on surfaces $(1,0)$

0 Eqn (10) reflecting boundary

1 Eqn (8) zero concentration

2 Eqn (9) Sievert's Law

3 Eqn (11) recombination

(FRQNT $=$ inner surface, BACK $=$ outer surface for cylindrical or spherical geometry).

$C O=S_{0}\left(9.0 \times 10^{-4}\right.$ atomic fract. $\left./ \mathrm{atm}^{1 / 2}\right)$

$E S \emptyset L=Q_{S}(0.091 \mathrm{eV})$

IGEQM $=$ determines geometry $(0)$

0 planar

1 cylindrical

2 spherical

$\mathrm{RO}=$ sample inner radius (ignored for planar) $(0.0 \mathrm{~cm}$ )

DEN = matrix density $\left(8.5 \times 10^{22}\right.$ atoms $\left./ \mathrm{cm}^{3}\right)$

MASS $=M \quad(2.0$ AMU $)$

STICK $=\alpha \quad(0.002)$

TRITIUM = .T. if tritium decay is to be included in trap number "KTRAP" (.F.) 
Next information defining program control is read from input in namelist format.

\section{\$CONTROL}

$N=$ number of spatial mesh points $(3 \leq N \leq 200)$ (100)

REPEAT $=$ number of cycles (i.e., repeats of the steps maximum of 5 steps

per cycle) (0)

NPREP = number of cycle edits (discussed below under output) (1)

FIMP = fraction of mesh points in implant (trap) region (0.25)

NOTE: A non-uniform mesh is generated by the program. The user must insure that the number of mesh points $N$ and the fraction of mesh points in the implant region FIMP are sufficiently large so that the results obtained are not mesh dependent. The appropriate values to use are problem dependent but it has been found that $N=100$ and FIMP $=0.25$ give deviations in release rate of $<10 \%$ for most problems.

Finally, information defining a series of $P, T$, implant steps is read from input in namelist format.

\$DATA

TEMPO = initial temperature $(300 . K)$

TIME = time for this step (1000. sec)

IMPRATE $=$ implant flux after reflection $\left(0.0\right.$ particles $\left./ \mathrm{cm}^{2}-\mathrm{sec}\right)$

RAMP = heating rate $(0.0 \mathrm{k} / \mathrm{sec})$

NEWRUN $=. T$. takes initial concentrations from SUBROUTINE INITC

.F. takes initial concentrations from previous step (.T.)

NPRINT = number of edits (discussed below under output) (40)

PO = initial gas pressure at front (inner) and back (outer) surfaces

$(0.0,0.0 \mathrm{~atm})$

PRAMP = pressure ramps at front (inner) and back (outer) surfaces

$(0.0,0.0 \mathrm{~atm} / \mathrm{sec})$ 
NOTE: Default values are given in ( ). Material default parameters are typical of an austenitic SS.

NOTE: The subroutine INITC is set up to initialize all concentrations to zero. This subroutine may easily be replaced by the user.

NOTE: The functions PRESSR and TEMPR are set up to do linear variations in pressure and temperature. These functions may easily be replaced by the user.

NOTE: The subroutine PLOTQ is set up as a dummy subroutine (except at SLL where it creates plots of the release rate vs. time (temperature)). The user may easily insert his own plotting routines here.

\section{B. Code Output}

Output begins with the values used in namelists "SAMPLE" and "CONTROL", followed by a list of the spatial variable at each mesh point (in $\AA$ ), $G(x)$ at each mesh point (normalized to 1.0 ), and $C_{T}^{j}(x)$ at each mesh point (atomic fract). If REPEAT $\neq 0$ a 7 ist of the steps to be repeated for each cycle (namelist "DATA") appears next. If REPEAT $=0$ namelist "DATA" is output before the output for the respective step.

The following output is created for NPRNT times (temperatures) at each step: (If REPEAT $\neq 0$ output is printed for NPREP uniformly spaced cycles) the integrated number of particles $/ \mathrm{cm}^{2}$ both trapped and diffusing in the sample; a scale factor for the release rate and integrated release; scaled release rates and integrated release at both surfaces; and concentrations (atomic fract.) of the diffusing and trapped particles at 
each mesh point. During implantation the scale factor is equal to the implant rate. During desorption it is set so that the integrated release over time equals one. 
IV. Sample Problems

A. Implant

Consider a $1 \mathrm{keV}$ implant of $10^{15} \mathrm{D}^{+} / \mathrm{cm}^{2}-\mathrm{sec}$ (after reflection) for 1000 seconds into a slab of stainless steel of thickness $1 \mathrm{~mm}$. The deuterium implant profile is determined through use of an appropriate range-straggling calculation, e.g. TRIM. Assume the implantation creates a steady state uniform trap concentration of $1 \%(0.9 \mathrm{eV}$ total energy) over the damaged region of the sample $(500 \AA)$. After implantation the sample is linear ramp heated at $1 \mathrm{~K} / \mathrm{sec}$ for 500 seconds. Data deck needed:

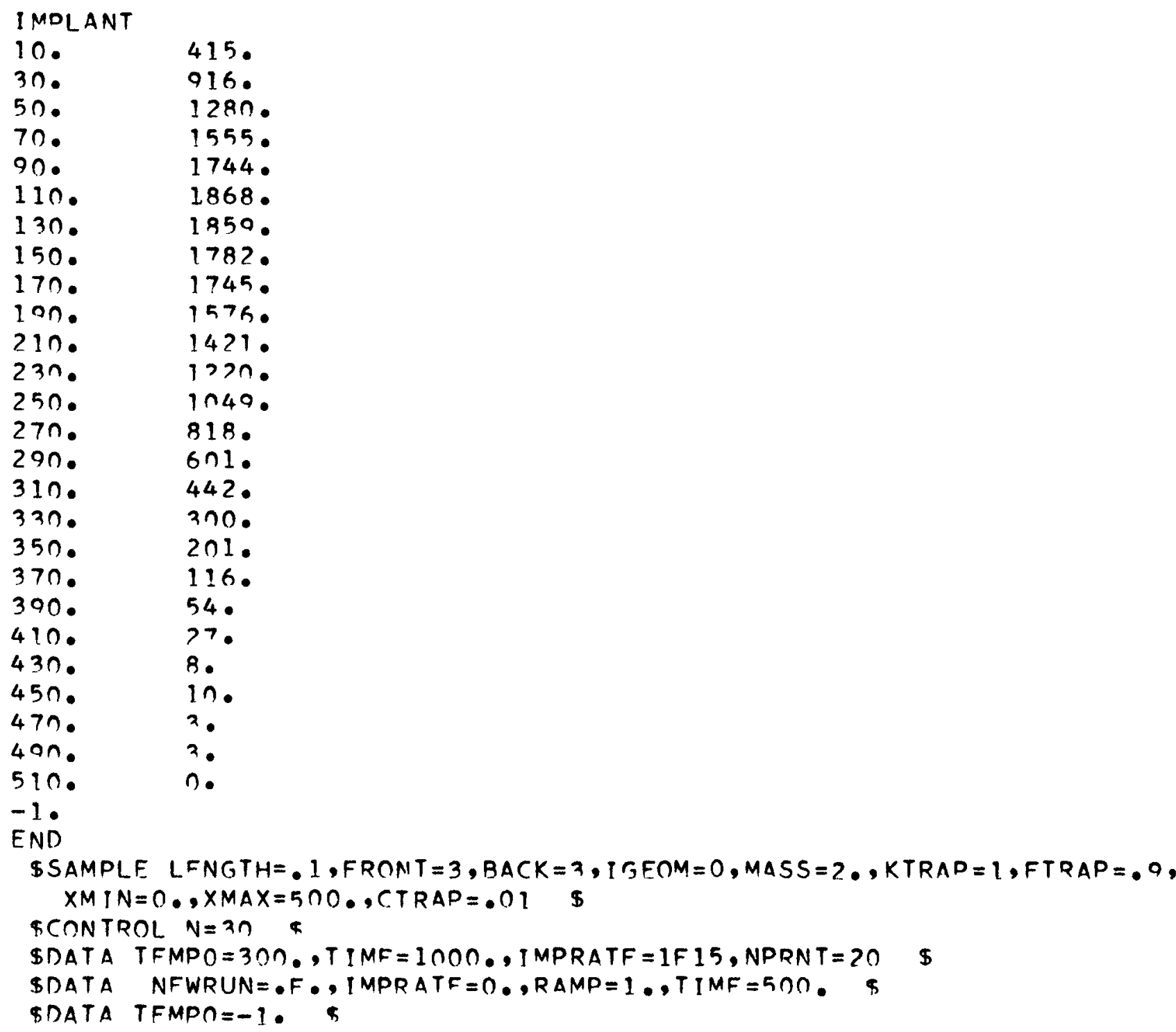




\section{B. Charge}

A hollow cylinder of SS with a $2 \mathrm{~cm}$ ID and a $2.2 \mathrm{~cm}$ OD is to be charged with $1 \mathrm{~atm}$. hydrogen at $300^{\circ} \mathrm{C}$ from the inside only for two hours. The cylinder and gas is then to be cooled to room temperature at $1 \mathrm{~K} / \mathrm{sec}$. It is then to be held at $300 \mathrm{~K}$ for 1 day with the external hydrogen removed.

Data deck needed:

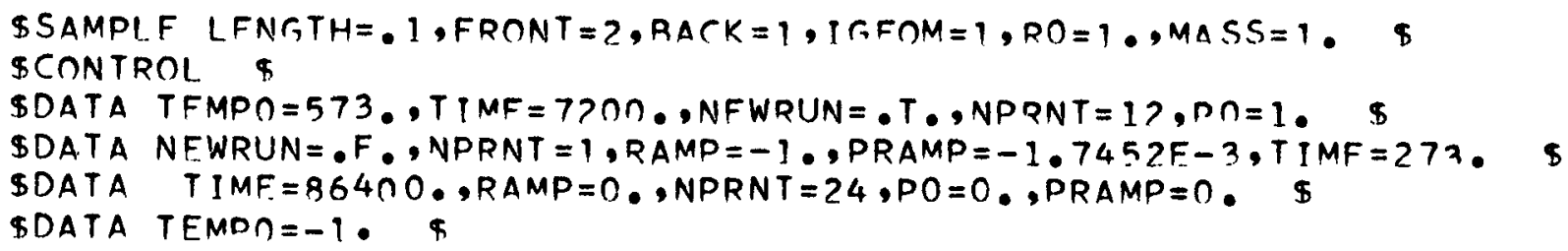




\section{Cycling}

The same sample as in $A$ is to be implanted with $1 \mathrm{keV} D^{+}$at $10^{16} \mathrm{D}^{+} / \mathrm{cm}^{2}-\mathrm{sec}$ for 10 seconds at $500 \mathrm{~K}$ and held at $500 \mathrm{~K}$ for 1000 seconds. This procedure is to be repeated ten times. Traps are nonuniform in depth.

Data deck needed:

\section{IMPLANT}

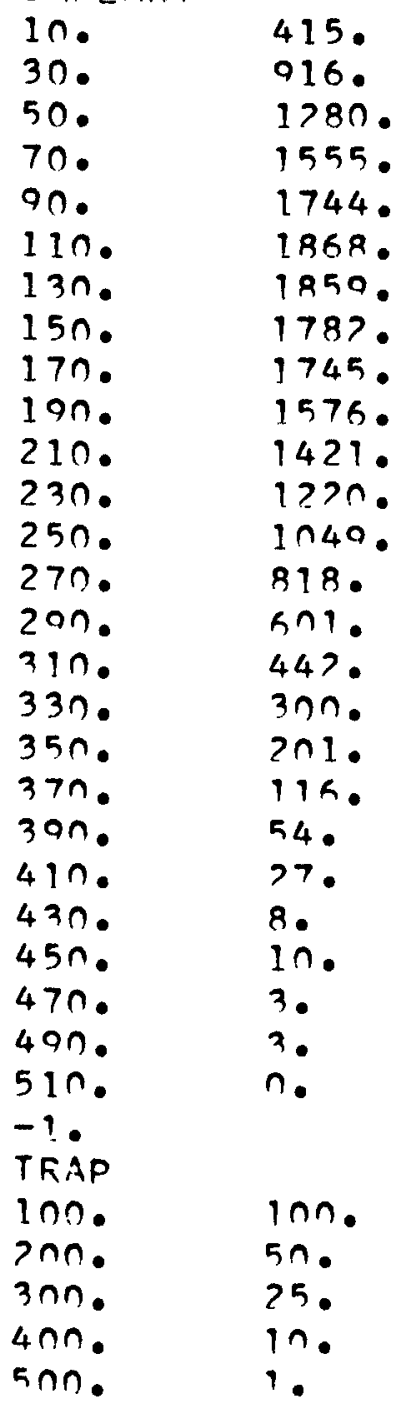

$-1 \cdot$

END

\$SAMPLF LFNGTH=1 , FRONT $=1$, RACK $=1, M A S S=1$, ,

KTRAP $=1$, FTRAP $=.9$, CTRAP $=.01 \$$

$\$ C O N T R O L$ REPFAT $=10, N D P E P=5, N=30 \quad \$$

\$DATA TFMPO $=500 .$, TIMF $=10 .$, IMPRATE $=1 F 16, \mathrm{~L}$ IMPRT $=. T ., N P R N T=0$

\$DATA IMPRATE $=0$. NEWRUN $=\bullet F .$, TIMF $=1000$

SDATA TFMPO $=-1 \cdot \$$ 


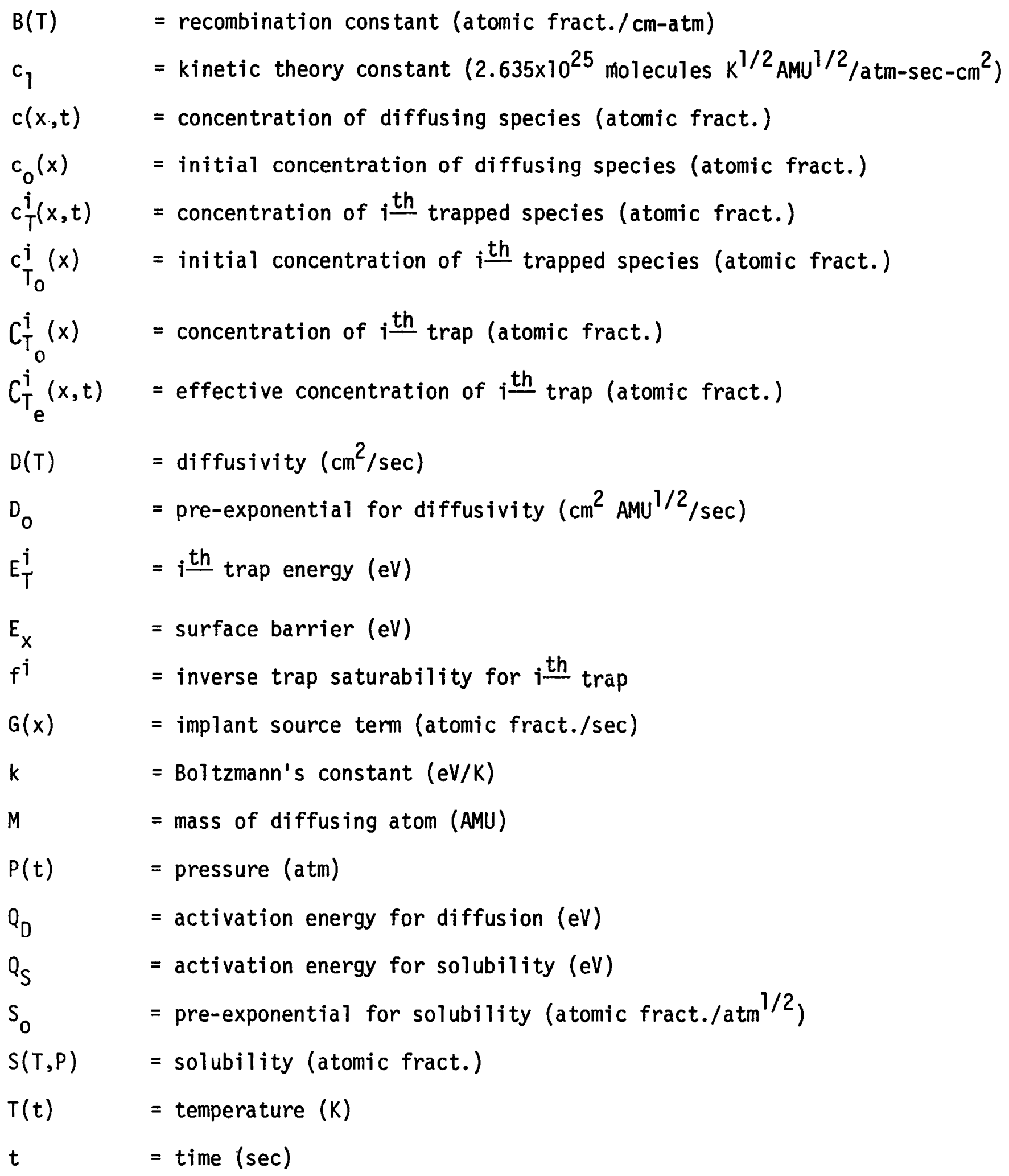




$\begin{array}{ll}x & =\text { spatial variable }(\mathrm{cm}) \\ x_{s} & =\text { spatial variable at surface }(\mathrm{cm}) \\ \alpha & =\text { sticking coefficient } \\ \gamma & =\text { tritium decay constant }\left(1.78 \times 10^{-9} \mathrm{sec}^{-1}\right) \\ \lambda & =\text { jump distance }(2.5 \AA) \\ \nu_{0} & =\text { detrapping attempt frequency }\left(10^{13} \mathrm{sec}^{-1}\right) \\ \rho & =\text { matrix density }\left(\text { atoms } / \mathrm{cm}^{3}\right)\end{array}$




\title{
APPENDIX A
}

\author{
Control cards to use DIFFUSE at SLL: \\ Job Card \\ Account Card \\ Plot ID Card (if plotting wanted) \\ ATTACH (LGØ, DRELLGO, ID=BASKES) \\ LGO. \\ PRPLOT. (Printer plots) \\ PLT75. (35 mm plots)
}


APPENDIX B

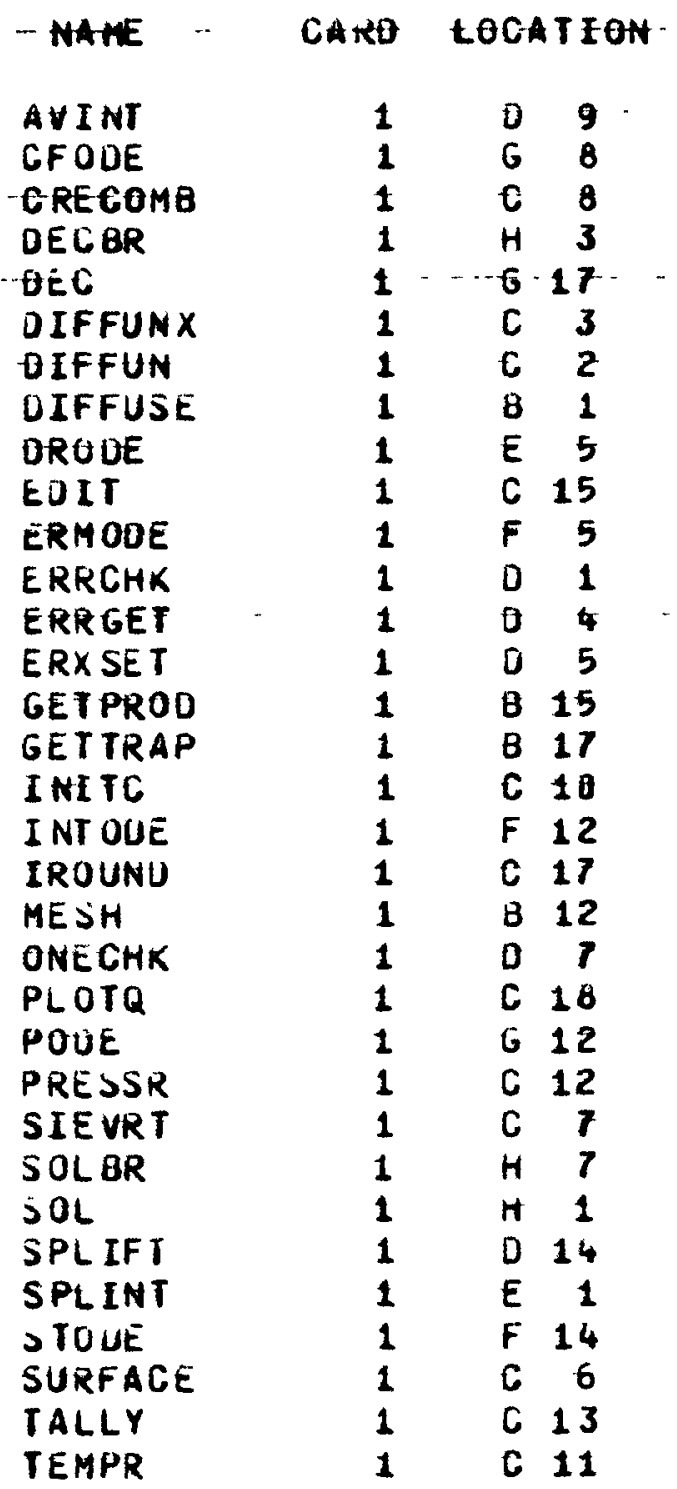


UNL IMITED RELEASE

INITIAL DISTRIBUTION

T. B. Cook, 8000; Attn: W. J. Spencer, 8100

A. N. Blackwel1, 8200

L. Gutierrez, 8400

B. F. Murphey, 8300; Attn: D. M. Schuster, 8310

T. S. Gold, 8320

G. W. Anderson, 8330

D. L. Hartley, 8350

W. Bauer, 8340

W. D. Wilson, 8341

M. I. Baskes, 8341 (50)

S. H. Goods, 8341

L. G. Haggmark, 8341

G. W. Look, 8341

G. J. Thomas, 8341

W. B. Gauster, 8347

K. L. Wilson, 8347

Technical Publications and Arts Division, 8265, for TIC (2)

P. Dean, 8265/Classification and Technical Library Processing Division, 3141

Classification and Technical Library Processing Division, 3141 (2)

Library and Security Classification Division, 8266-2 (3) 